\title{
Pharmaciana
}

Vol.10, No.2, July 2020, Page. 219-230

ISSN: 2088 4559; e-ISSN: 24770256

DOI: $10.12928 /$ pharmaciana.v10i2.16427

\section{Camellia sinensis extract phytosomes inhibit body weight gain in Sprague-Dawley rats}

\author{
Dwi Kurnia Putri ${ }^{1}$, Iskandarsyah ${ }^{* 2}$, Effionora Anwar ${ }^{2}$ \\ ${ }^{1}$ Department of Herbal, Faculty of Pharmacy, Universitas Indonesia, \\ Pondok Cina, Beji, Depok, West Java, Indonesia \\ ${ }^{2}$ Department of Technology Pharmacy, Faculty of Pharmacy, Universitas Indonesia, \\ Pondok Cina, Beji, Depok, West Java, Indonesia
}

Submitted: 18-04-2020

Reviewed: 19-05-2020

Accepted: 30-06-2020

\begin{abstract}
A phytosome is a kind of nanovesicle lipids to increase the absorption of active substances. Green tea extract was formulated into phytosome to find out its ability to inhibit weight gain. There were three formulas with thin layer hydration. Furthermore, phytosome complex formation, morphology, particle size, zeta potential, and polydispersity index, and absorption efficiency test were characterized. Phytosomes and green tea extracts were tested for absorption in vitro. A total of 25 rats were divided into five test groups, which were the normal group, placebo group, orlistat group, green tea extract group, and phytosome group. For 8 weeks they were orally induced using $10 \%$ of fructose $+2 \%$ of cholesterol, and test treatment. The best characteristics of FIII were formed complex, spherical morphology, Dv90 $782.67 \pm 39.7 \mathrm{~nm}$, polydispersity index of $56 \pm 0.11$, zeta potential of $70.83 \pm 1.67 \mathrm{mV}$, and adsorption efficiency of $97.77 \pm 2.66 \%$. The test on the animals at week 8 resulted in percentage of weight gain in normal treatment of $46.47 \pm 17.48 \%$, placebo of $101.17 \pm$ $10.37 \%$, orlistat of $42.51 \pm 25.13 \%$, green tea extract of $92.73 \pm 36.43 \%$, and phytosomes of $45.09 \pm$ $15.56 \%$. Green tea extract flux was $2316.2 \pm 1309.8 \mu \mathrm{g} / \mathrm{cm} 2 /$ hour, while phytosome flux was $3125.3 \pm$ $2071.8 \mu \mathrm{g} / \mathrm{cm}^{2} /$ hour. To sum up, phytosomes can inhibit weight gain and are better than to green tea extracts $(\mathrm{p}<0.05)$.
\end{abstract}

Keywords: obesity, EGCG, phytosome, cholesterol

\footnotetext{
*Corresponding author:

Iskandarsyah

Department of Technology Pharmacy, Universitas Indonesia

Pondok Cina, Beji, Depok, West Java, Indonesia

Email: Aya_2803@yahoo.com
} 


\section{INTRODUCTION}

Weight is a parameter developing with age. Its development can occur normally or abnormally. Abnormally, weight can experience a very rapid increase leading to overweight and obesity (Rahmanisa et al., 2007). Obesity is overweight due to the accumulation of body fat because the energy absorbed is more than the energy released and is also one of the health problems in the world community. In Indonesia, obesity periodically experienced an increasing trend in adults from 2007 to 2018 with a prevalence of $10.5 \%$ in 2007, 14.8\% in 2013, and 18\% in 2017 (Riskesdas, 2018). Asians are considered obese if they have a Body Mass Index (BMI) $\geq 25 \mathrm{~kg} / \mathrm{m} 2$ (Dewi, 2008).

Green tea is a plant that has been widely tested both preclinically and clinically to lose weight (Dewi, 2008; Nagao et al., 2007). Its extract has the main content of polyphenols catechins which are Epigallocatechin-3-gallate (EGCG), Epigallocatechin (ECG), and Epicatechin (EC). EGCG is the largest content which is $80 \%$ of the total available catechins (Dewi, 2008). EGCG reduces lipid absorption by inhibiting phospholipase A2 and increasing lipid metabolism (Anand et al., 2017). Catechins (EGCG) have hypocholesterolemic effects, because EGCG can suppress the absorption of cholesterol in the intestine (Zheng et al., 2004 and Sayama et al., 2000).

Regardless of its therapeutic potential, EGCG is a catechin compound easily degraded due to oxidation and epimerization processes (Gadkari et al., 2017). Based on the review of Anand et al (2017), it was stated that the low absorption of green tea in the intestinal tract is due to unstable EGCG. The stability of catechins is strongly influenced by concentration in solution, exposure to light, and oxygen (Zhu et al., 1997; Puligundla et al., 2017). Besides, EGCG is a hydrophilic polyphenol group with water solubility $531.7 \mathrm{~g} / \mathrm{L}$, so that the absorption capacity of cell membranes and bioavailability is very low $(<5 \%)$ because of a lot of elimination in the body (Anwar and Farhana, 2018; Legeay et al., 2015; Krook and Hagerman, 2012; Patel et al., 2009) Therefore, to increase absorption of EGCG, nanovesicel lipids need to be made to penetrate the lipid bilayer walls of small intestinal cells. Development of nanocarriers including phytosomes can increase the absorption of EGCG which results in increased bioavailability. Phytosomes are a technology to deliver active substances using phospholipids (lipid carriers) by forming complexes of active substances (phytoconstituents) in them so that phytosomes are very compatible with human physiological systems (Kumar et al., 2017).

This study will examine the benefits of phytosomes that contain green tea leaf extract as a weight loss and its effect on lipid profiles in rat.

\section{MATERIALS AND METHOD \\ Materials}

Green tea leaf extract (Camellia sinensis (L) Kuntze) containing tea polyphenols of $98.12 \%$ and epigallocatechin gallate of $47.09 \%$ was obtained from Andi Biotech (Xi'an) co ltd. The test animals used were Sprague-dawley male rats weighing 100-200 grams, 6 weeks of age obtained from veterinary medicine of IPB.

\section{Methods \\ EGCG assay in green tea leaf extract using HPLC}

The mobile phase was a mixture of $0.05 \%$ acetic acid: acetonitrile $(87: 13 \mathrm{v} / \mathrm{v})$ with a flow rate of $1 \mathrm{~mL} / \mathrm{min}$ and a wavelength of $280 \mathrm{~nm}$ (Fangueiro et al., 2014). The standard concentrations used were 3 ppm, 6 ppm, 13 ppm, $25 \mathrm{ppm}, 50 \mathrm{ppm}$ and $100 \mathrm{ppm}$. Determination of the levels of green tea extract used a solution of green tea leaf extract with a concentration of $50 \mathrm{ppm}$ in triplo.

\section{Green tea extract phytosome formulation}

The method used was thin layer hydration (Lestari et al., 2017). Phospholipids were dissolved in dichloromethane organic solvents, and green tea leaf extract was dissolved in $96 \%$ ethanol solvent. Then, they were mixed into a round bottom flask. Furthermore, evaporation with a rotary evaporator 
lasted 2 hours at $39^{\circ} \mathrm{C}$. After it formed a thin layer, it was drained with nitrogen gas and stored in the refrigerator for 24 hours. Hydration was done by adding phosphate buffer $\mathrm{pH} 7.4$ as much as $25 \mathrm{~mL}$ and using glass beads to peel away the layer of fat attached to the round rounded bottom flask. The composition of phytosomes can be seen in Table 1 .

Table 1. Green tea extract phytosome formulas

\begin{tabular}{lccc}
\hline Materials & FI & FII & FIII \\
\hline Green tea leaf extract & Equal EGCG $300 \mathrm{mg}$ & (528 mg of green tea extract) \\
Ekstract ratio : phospolipids & $1: 2$ & $1: 2.5$ & $1: 3$ \\
Phosphate buffer pH 7.4 & Ad 25 mL & Ad $25 \mathrm{~mL}$ & Ad $25 \mathrm{~mL}$ \\
\hline
\end{tabular}

\section{FTIR analysis}

Phytosome powder that had been dried was mixed with $\mathrm{KBr}$ crystals in a ratio of 1: 100 . The mixture was then crushed to a fine powder and inserted into the disc. Samples were analyzed by FTIR with wave numbers of 400 to $4000 \mathrm{~cm}-1$ (Maryana et al., 2016).

\section{Phytosome morphology}

A few drops from each formulation were placed on the carbon copper-coated grid and left to form a thin film layer on the grid. The film was then viewed under the Transmission Electron Microscope (TEM) and magnified at the appropriate magnification (Gupta and Dixit, 2011).

\section{Particle size distribution, zeta potential, and polydispersity index}

Phytosomes suspension was centrifuged for 30 minutes. Then, $1 \mathrm{~mL}$ of sample with $10 \mathrm{ml}$ of aquadest was dissolved, $5 \mathrm{ml}$ of the sample solution was transferred to the cuvette, and zeta potential was measured by Particle Size Analyze (PSA) with the Dynamic Light Scattering (DLS) method.

\section{The entrapment efficiency of phytosome}

The method used was an indirect method. A phytosome suspension of $1 \mathrm{~mL}$ was mixed into 2 $\mathrm{mL}$ of dichloromethane in a $5 \mathrm{~mL}$ measuring flask. Supernatants were obtained by centrifuging $1 \mathrm{~mL}$ of phytosomes at a speed of $12000 \mathrm{rpm}$ at 4 degrees for 90 minutes. Then, $0.5 \mathrm{~mL}$ of the resulting supernatant was taken and methanol was added to $10 \mathrm{ml}$ in a volumetric flask. Finally it was analyzed using HPLC.

$$
\text { Entrapment Ef diciency }(\%)=\frac{\text { Total ECCG in the microspheres }-E G C G \text { concentration in the supernatan }}{\text { Kador EGCG totalotal ECCG in the microspheres }} 100 \%
$$

\section{Absorption of EGGC In Vitro \\ Measurement of absorbed EGCG was carried out using Franz diffusion cells. The membrane used was inverted goat intestine placed in a phosphate buffer receptor compartment $\mathrm{pH} 7$ containing $1 \%$ methanol. Methanol was added to increase the solubility of EGCG. The test was carried out for 10.5 hours based on the EGCG data eliminated at 3.5 hours after consumption, so the measurement was done 3 times from the time of elimination.}

\section{Weight loss test and lipid profile against test animals}

This study has passed the ethical review from the Faculty of Medicine, Universitas Indonesia with the number 1287/UN2.F1/ETIK /2018. The test animals used were 25 male Sprague-dawley strain rats which were divided into $5(\mathrm{n}=5)$, fed based on standard of ad libitum and treated such as Table 2 for 8 weeks. Every week the rats were weighed to discover the weight gain of the rat. 


\begin{tabular}{|c|c|c|c|}
\hline Groups & & eatments & Evaluations \\
\hline Normal & CMC-Na & ad libitum feed & $\begin{array}{l}\text { 1. Measurement of percentage } \\
\text { of weight loss }\end{array}$ \\
\hline Placebo & CMC-Na & \multirow{4}{*}{$\begin{array}{l}10 \% \text { of Fructose diet } \\
\text { (Andriany, 2015) \& } \\
1 \% \text { of cholesterol } \\
\text { (Ahmad et al., 2015) }\end{array}$} & 2. Total cholesterol level \\
\hline Orlistat & $\begin{array}{l}32.4 \text { of orslistat } \\
\mathrm{mg} / \mathrm{kgBB} \text { of } \\
\text { rats }\end{array}$ & & \\
\hline $\begin{array}{l}\text { Green tea } \\
\text { extract }\end{array}$ & $\begin{array}{l}\text { Green tea } \\
\text { extract } \\
\text { containing } \\
\text { EGCG 52.47 } \\
\mathrm{mg} / \mathrm{kgBW}\end{array}$ & & \\
\hline $\begin{array}{l}\text { Phytosome } \\
\text { of Green } \\
\text { Tea Extract }\end{array}$ & $\begin{array}{l}\text { Suspension of } \\
\text { green tea } \\
\text { phytosome } \\
\text { containing } \\
52.47 \mathrm{mg} \mathrm{/} \\
\mathrm{kgBW} \text { of } \\
\text { EGCG }\end{array}$ & & \\
\hline
\end{tabular}

\section{Rat blood serum examination}

Test rats were fasted for 12-18 hours, then their blood was drawn into the orbital sinus vein using a capillary tube with a diameter of $\pm 1 \mathrm{~mm}$ accommodated in $\pm 1.5 \mathrm{cc}$ microtubes. Previously rats had been anesthetized using ether. Microtubes containing blood samples were allowed to stand for 20 minutes to freeze completely, then centrifuged at $3000 \mathrm{rpm}$ for 15 minutes. Clear serum would form at the top and so would sediment at bottom. Then the serum formed was taken for testing of total cholesterol.

\section{Total cholesterol level}

The method used was Cholesterol Oxidase-peroxidase aminoantypirin phenol (CHOD-PAP): enzymatic photometric test. The test used a spectrophotometer with a wavelength of $546 \mathrm{~nm}$. The blank was in the form of aquadest as much as $10 \mu \mathrm{l}$ and reagent as much as $1000 \mu \mathrm{l}$. The sample or standard was used as much as $10 \mu \mathrm{l}$ and was mixed with reagent as much as $1000 \mu$. The test sample was incubated for 10 minutes at $37^{\circ} \mathrm{C}$, then the results were read. Read the absorbance with a blank reagent in 60 minutes. Total cholesterol levels can be calculated using the following equation.

$$
\text { Cholesterol }(\mathrm{mg} / \mathrm{dL})=\frac{\text { A sampel }}{\text { A standard }} x \text { Standard concentration cholesterol }(\mathrm{mg} / \mathrm{dL})
$$

\section{Data Analysis}

Data analysis was conducted statistically using software of IBM SPSS Statistics version 22. Testing was performed with a $95 \%$ confidence level. Normal body mass index test data and serum lipid profile of rats used Shapiro-Wilk because the number of samples was less than 50. Then repeated statistical t-test analysis was performed with post-Hock LSD analysis to figure out differences in body weight and lipid profiles of test animals between the groups every week of measurement of overall significance $(\mathrm{p}<0.05)$. 


\section{RESULT AND DISCUSSION}

\section{EGCG assay in green tea extract}

The test was done by injecting the standard EGCG 6 times in a row, EGCG peak appeared after $15.39 \mathrm{~min}$. The determination of the calibration curve was obtained from the relationship between the $\mathrm{x}$-axis which described the concentration and the $\mathrm{y}$-axis as the area. The linear regression equation obtained was $y=21176 x-12485$ with a correlation coefficient value $r=0.9999$. This showed that the calibration curve obtained is linear, which is close to 1 . After obtaining the calibration curve, the next step was to determine the level of EGCG content of green tea leaf extract. The results obtained were $56.82 \pm 0.16 \%$. The result of determining the content obtained exceeds the EGCG content contained in the leaf green tea extract analysis certificate, that is $47.09 \%$. This is likely due to the condition the analysis used in this study is different from the analysis conditions by manufacturers of green tea leaf extract.

Green tea extract phytosome formulation results. The results of the formulations of the three formulas showed that all of the formulas, the mole ratio of 1:2, 1:2.5, and 1:3, are homogeneous suspensions. The resulting phytosome suspension has a distinctive smell of tea, brick brown color, and a slightly bitter taste like tea in general. For the resulting phytosome suspension, phytosome characterization testing was carried out. The results can be seen in Figure 1.

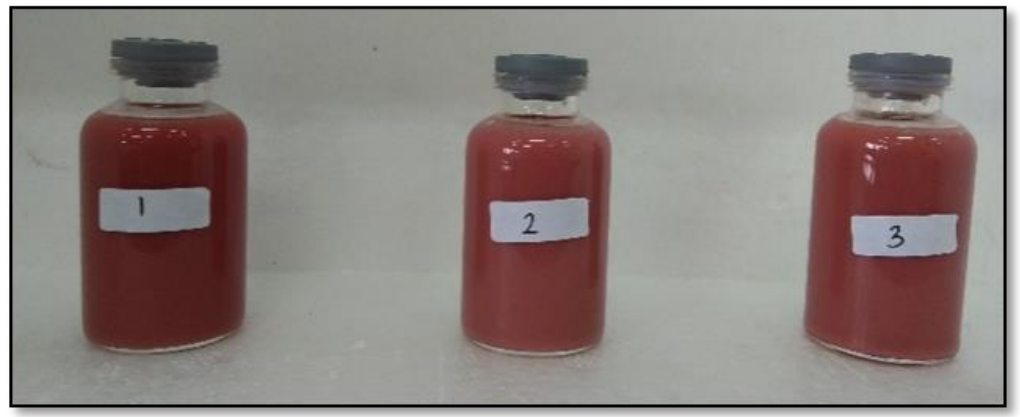

Figure 1. Phytosome formulation results of green tea extract FI, FII, FIII

\section{Morphology}

Morphological analysis was carried out using a transmission electron microscope (TEM), where the results of the analysis showed that the phytosome had a spherical shape. The results of morphological analysis can be seen in Figure 2. FIII phytosomes had the largest size of all the formulas because of the mole ratio at the time of formulation. Also, FIII was the formula with the largest mole ratio of EGCG: phosphatidylcholine which equal to 1: 3 .

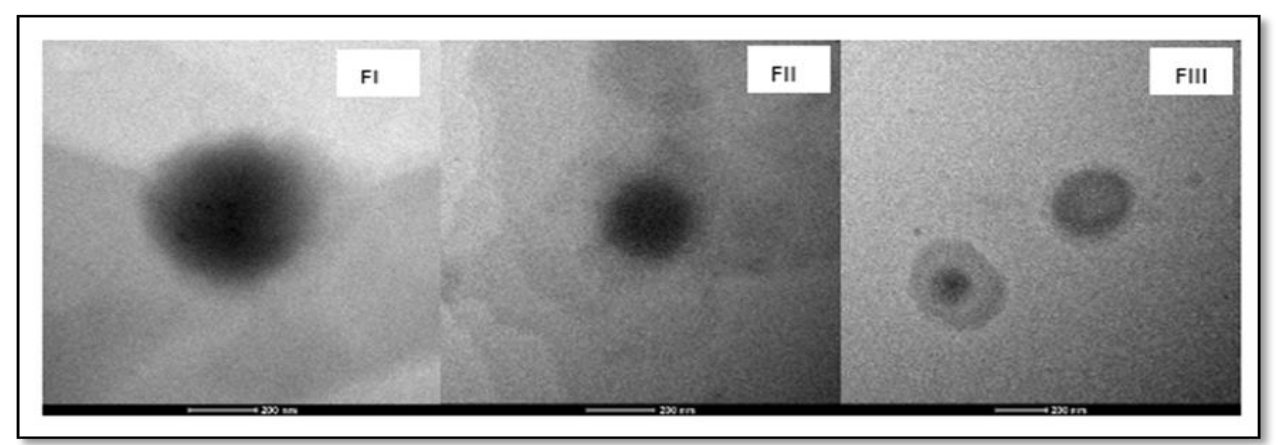

Figure 2. Morphology of green tea extract phytosomes viewed under the Transmission Electron Microscope (TEM) 


\section{Particle size distribution, zeta potential, and polydispersity Index}

Particle size is one of the physical characteristics that need to be considered to see the stability of the particulate preparations (Malvern Instruments Ltd, 2015). In this study, particle size distribution was measured using Particle Size Analyzer (PSA) with the Dynamic Light Scattering (DLS) method. Phytosome suspensions were first sonicated for 30 minutes to reduce particle size. The results of data measurement in each of the formulas can be seen in Table 3 and Figure 3.

Table 3. Particle size, zeta potential, and polydisperty index

\begin{tabular}{llll}
\hline Formula & FI & FII & FIII \\
\hline PDI & $0.58 \pm 0.01$ & $0.57 \pm 0.03$ & $0.56 \pm 0.11$ \\
Zeta Potential & $-77.97 \pm 1.56$ & $-74.23 \pm 1.56$ & $-70.83 \pm 1.67$ \\
Partice size & $303.3 \pm 10.85$ & $388.73 \pm 15.73$ & $549.33 \pm 8.96$ \\
\hline
\end{tabular}

Particle size distribution can be seen in Table 4 below showing that $90 \%$ of the existing particle size has a size of $1105 \pm 154.03$, which is very different from the smallest Zaverage acylation of 303.3 \pm 10.85 . FII and FII phytosomes have particle sizes at Dv 90 respectively $754.33 \pm 49.44$ and $782.67 \pm$ 39.7 .

Table 4. Particle size distribution based on green tea extract phytosome volume

\begin{tabular}{llll}
\hline Formula & Dv10 $(\mathbf{n m})$ & Dv50 $(\mathbf{n m})$ & Dv90 $(\mathbf{n m})$ \\
\hline FI & $106.13 \pm 14.59$ & $591.67 \pm 30.4$ & $1105 \pm 154.03$ \\
FII & $59.7 \pm 26.9$ & $329.33 \pm 173.37$ & $754.33 \pm 49.44$ \\
FIII & $99.5 \pm 6.94$ & $496.33 \pm 14.36$ & $782.67 \pm 39.7$ \\
\hline
\end{tabular}

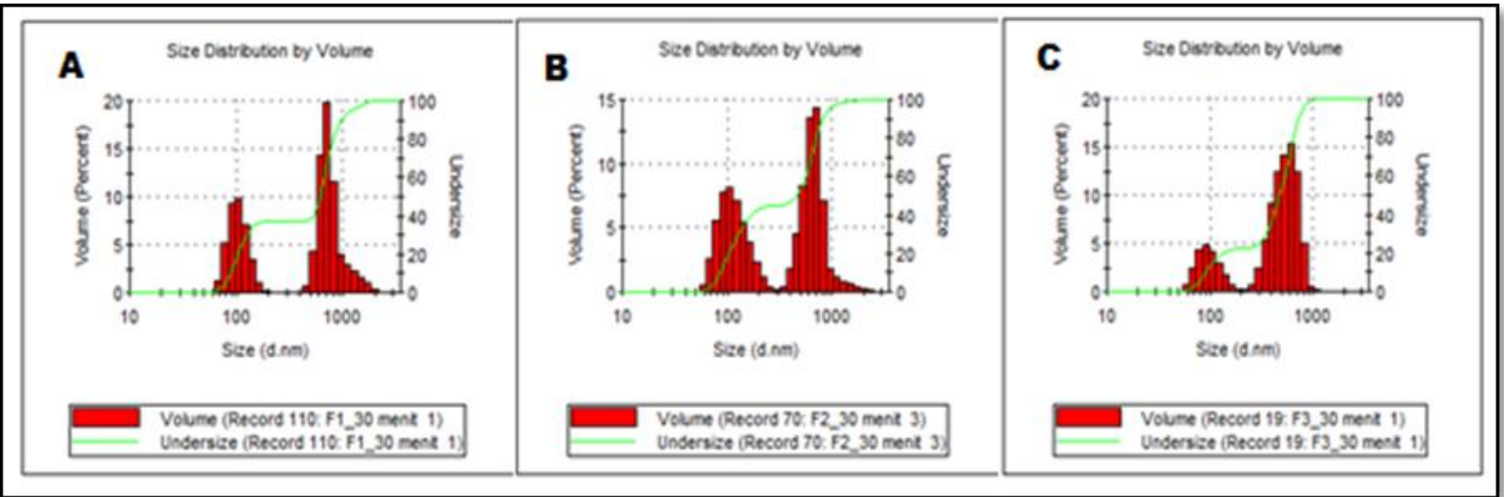

Figure 3. Graph of particle size based on volume of green tea extract phytosomes FI (A), FII (B), and FIII (C)

\section{Entrapment efficiency}

The adsorption efficiency test was carried out to discover the percentage of active substances formed complex with lipids in phytosomes. The measurement resulted in that the efficiency of adsorption from the highest to the lowest was FIII $97.77 \pm 2.66 \%$, FII $96.88 \pm 0.04 \%$, and FI $90.33 \pm$ 0.12. This is in accordance with the fact that more phospholipids can react and make complex with EGCG from green tea extracts. 


\section{Fourier transformation infrared spectroscopy (FTIR)}

FTIR analysis in this study was used to find out the complex formation between green tea extracts and phospholipids (Maryana et al., 2016). The results of the FTIR analysis showed the spectrum of the $-\mathrm{OH}$ group from extracts and phospholipids was seen at $3370 \mathrm{~cm}^{-1}$ and $3365.2 \mathrm{~cm}^{-1}$. When viewed from the phytosome -OH group a wave shift and a decrease in the peak intensity of the $\mathrm{OH}$ group occurred. This indicates that there was an interaction between the hydroxyl group and phosphate from phospholipids. Phytosomes showed the $-\mathrm{OH}$ group at $3267.5 \mathrm{~cm}^{-1}$. In addition, there was a decrease in the intensity of the $-\mathrm{CH}$ group $\left( \pm 3000 \mathrm{~cm}^{-1}\right.$ wave), the $-\mathrm{C}=\mathrm{O}$ group (wavelength \pm $1700 \mathrm{~cm}^{-1}$ ), the phosphate group (wavelength $\pm 1200 \mathrm{~cm}^{-1}$ ) in the phytosome spectrum. The results of the FTIR analysis of the three formulated formulas can be seen in Figure 4.

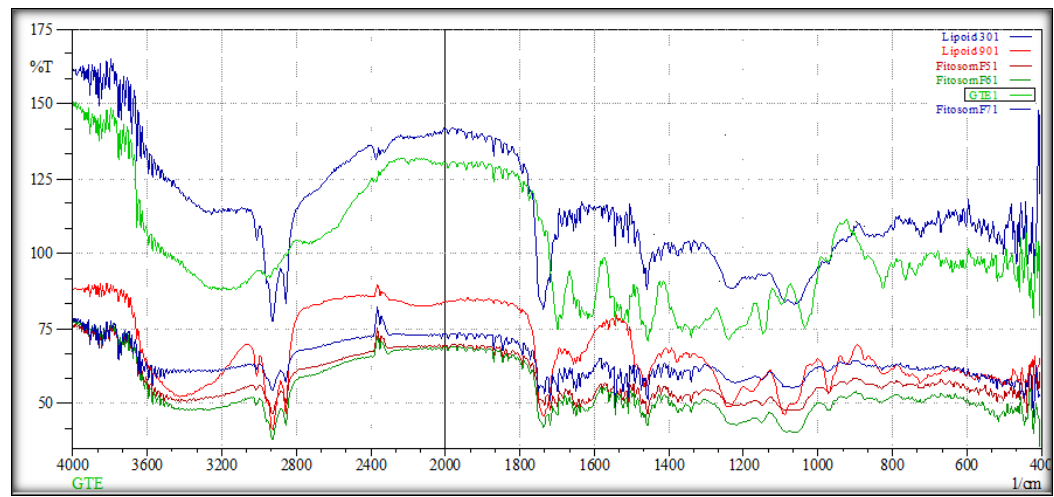

Figure 4. FTIR spectra of phospholipid G 90 and P 30, green tea extracts, and phytosomes

\section{Measurement results of In Vitro EGGC absorption}

The absorption for 10.5 hours resulted in 8 sampling points, the cumulative amount for green tea extract of $30718.28 \pm 12461.41 \mu \mathrm{g} / \mathrm{cm}^{-2}$, and the phytosome suspension of $22118 \pm 10431.35 \mu \mathrm{g} / \mathrm{cm}^{-2}$. Based on these results, the amount of EGCG absorbed from phytosomes is higher than that of green tea extracts. The results can be seen in figure 5. The rate of drug release or often referred to as the flux value $\left(\mu \mathrm{gcm}^{-2}\right.$.hour 1) was obtained from the slope in a steady state in accordance with the laws of Fick I. From the data, Flux for green tea extract amounts to $2316.2 \pm 1309.8 \mu{\mathrm{g} . \mathrm{cm}^{-2} \text {.hour }}^{1}$, while phytosomes amounts $3125.3 \pm 2071.8$. The study Koch et al (2018) showed concentration of catechins in green tea infusion is about $3250-4410 \mathrm{mg} / \mathrm{L}$. EGCG released from phytosomes is more than that from extras. This indicates that phytosome preparations increase the amount of drug absorbed each time unit, sustainable release and cell membrane permeation, resulting in increased absorption (Cai et al., 2018). The results can be seen in Figure 5.

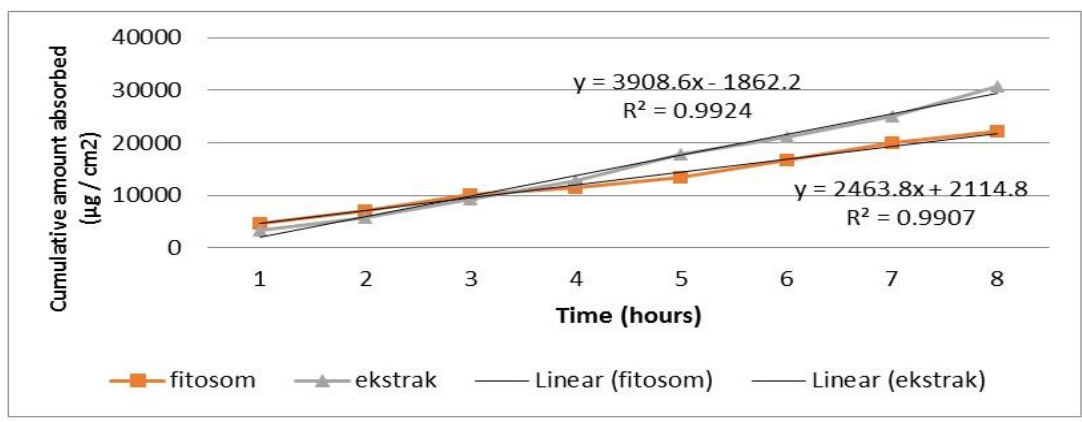

Figure 5. Graph of the cumulative amount of EGCG absorbed from green tea extract and green tea extract phytosome 


\section{Weight gain measurement results}

In vivo studies to increase body weight of rats used $10 \%$ fructose and $2 \%$ pure cholesterol for 8 weeks. Test animals were fed through tube orally using the two mixtures and were given CMC-Na preventive treatment for the normal and placebo groups, using orlistat, the green extract, and the green extract phytosome. Graph of weight gain can be seen in Table 5. In the first week the percentage of weight gain increases, then decreases in the second week, then increases again in the third week and decreases back in the fourth week, then constant increases from the fifth week to the eighth week. In the orlistat group the percentage of weight gain of rats 1 and 2 weeks decreases, then rises from the fourth week to the ninth week, then drops in the seventh week and experiences a small percentage of weight gain in the eighth week. Green tea extract group experiences a percentage increase in body weight from week 1 to week 8 . The percentage of weight gain in the phytosome group of green tea extracts from the 1 st to 3 rd weeks increases, in the 4th to 5th weeks, they experience an increase, then increase to the 8th week. However, the phytosome group cuts the percentage of weight gain compared to the orlistat group at the seventh week.

Statistical test results showed a significant difference $(p<0.05)$ between the placebo group and the normal group, meaning that the induction using fructose $10 \%$ and cholesterol succeeded in increasing the body weight of mice after being tested for 8 weeks. The results of the statistic of the green tea extract group against the normal group, the orlistat group, and the phytosome group of green tea extract were significantly different $(\mathrm{p}<0.05)$, meaning that the green tea extract group had the ability to inhibit the weight gain of rat no better when compared to the orlistat group and the phytosome group of green tea extracts.

Table 5. The weight gain of green tea extract phytosome treated rat

\begin{tabular}{|c|c|c|c|c|c|c|c|c|c|}
\hline & \multirow{2}{*}{ Group } & \multicolumn{8}{|c|}{ Percent gain in weight $(\%)$ week to- } \\
\hline & & 0 & 1 & 2 & 3 & 4 & 5 & 7 & 8 \\
\hline Normal $^{\mathrm{b}, \mathrm{d}}$ & & 0.00 & 14.37 & 1.22 & 5.26 & 10.94 & 10.56 & 36.14 & 46.47 \\
\hline Placebo $^{\text {a }}$ & & 0.00 & 5.72 & -6.75 & 15.24 & 7.90 & 48.98 & 96.87 & 101.17 \\
\hline Orlistat $^{\mathrm{d}}$ & & 0.00 & -9.78 & -13.24 & 18.69 & 31.96 & 44.59 & 37.07 & 42.70 \\
\hline Green tea extra & $\operatorname{tract}^{\mathrm{a}, \mathrm{c}, \mathrm{e}}$ & 0.00 & 5.97 & 19.39 & 32.88 & 57.79 & 81.50 & 86.23 & 92.73 \\
\hline $\begin{array}{l}\text { Green tea extra } \\
\text { phytosome }^{\mathrm{d}}\end{array}$ & ract & 0.00 & 5.79 & 14.42 & 22.51 & 22.22 & 20.27 & 34.62 & 45.09 \\
\hline $\begin{array}{cc}\text { Information: } & \mathrm{a} \\
& \mathrm{b} \\
& \mathrm{c} \\
& \mathrm{d} \\
& \mathrm{e}\end{array}$ & $\begin{array}{l}\text { a. signifi } \\
\text { b. signifi } \\
\text { c. signifi } \\
\text { d. signifi } \\
\text { e. signifi }\end{array}$ & $\begin{array}{l}\text { ent fr } \\
\text { ent fr } \\
\text { ent fro }\end{array}$ & $\begin{array}{l}\text { the } \mathrm{n} \\
\text { the } \mathrm{p} \\
\text { the } \mathrm{o}\end{array}$ & $\begin{array}{l}\text { al group ( } \\
\text { bo group } \\
\text { t group }(\end{array}$ & $\begin{array}{l}0.05) \\
<0.05) \\
0.05) \\
\text { roup }(\mathrm{p} \\
\text { hytosom }\end{array}$ & $\begin{array}{l}\text { 05) } \\
\text { oup }\end{array}$ & $0.05)$ & & \\
\hline
\end{tabular}

As for the phytosome group of green tea extract, its ability to inhibit weight gain when compared to the orlistat group did not experience a significant difference $(\mathrm{p}>0.05)$, but from the 4th week to the 8th week, the percentage of weight gain in the phytosome group of the tea extract green was smaller than that in the orlistat group because orlistat can inhibit the activity of the pancreatic lipase enzyme which catalyzes the hydrolysis of triglycerides in the intestine into monoglycerides and 2 free fatty acids, so that fat absorption was inhibited and increaseed fat excretion through feces. Similarly, the green tea extract phytosome group when compared with the normal group, its ability to prevent weight gain statistically did not obtain significantly different results $(\mathrm{p}>0.05)$. However, at the 7th and 8th week the percentage of weight gain in the green tea extract phytosome group was smaller that of the normal group. Review Hodgson et al (2013) Green tea extract has been shown can be increase fat oxidation at rest and during exercise. Green tea extract after consumption 60-120 
minutes has conjugation on liver and gut microbiota (Kroon et al., 2004). The bioavailability of free EGCG concentration < 5\% in plasma (Cai et al., 2018). Mechanisms involving EGCG in weight loss is decreased absorption of lipids and proteins in the intestine, thus reducing calorie intake and activation of AMPK in liver, skeletal muscle, and white adipose tissue (Li et al., 2018 and Yang et al., 2016).

\section{Measurement results for total cholesterol}

In the measurement of total cholesterol parameters in rats induced by $10 \%$ of fructose and $2 \%$ of cholesterol for 8 weeks of observation, there was an increase and decrease every week that can be seen in Figure 6. In the last observation, which was the week after weeks 5 to 8 the total cholesterol of the phytosomes group decreased because EGCG can suppress the absorption of cholesterol in the intestine (Zheng et al., 2004). EGCG could decrease lipogenesis by inhibiting the activity expression of lipogenic enzymes, such as fatty acid synthase (Moon et al., 2007). Research conducted by Li et al (2018) shows that EGCG significantly reduced fat accumulation in epididymal fat tissues, but not in subcutaneous fat tissues, this matter indicate that EGCG reduce obesity might mainly via reducing lipid accumulation in epididymal fat tissue.

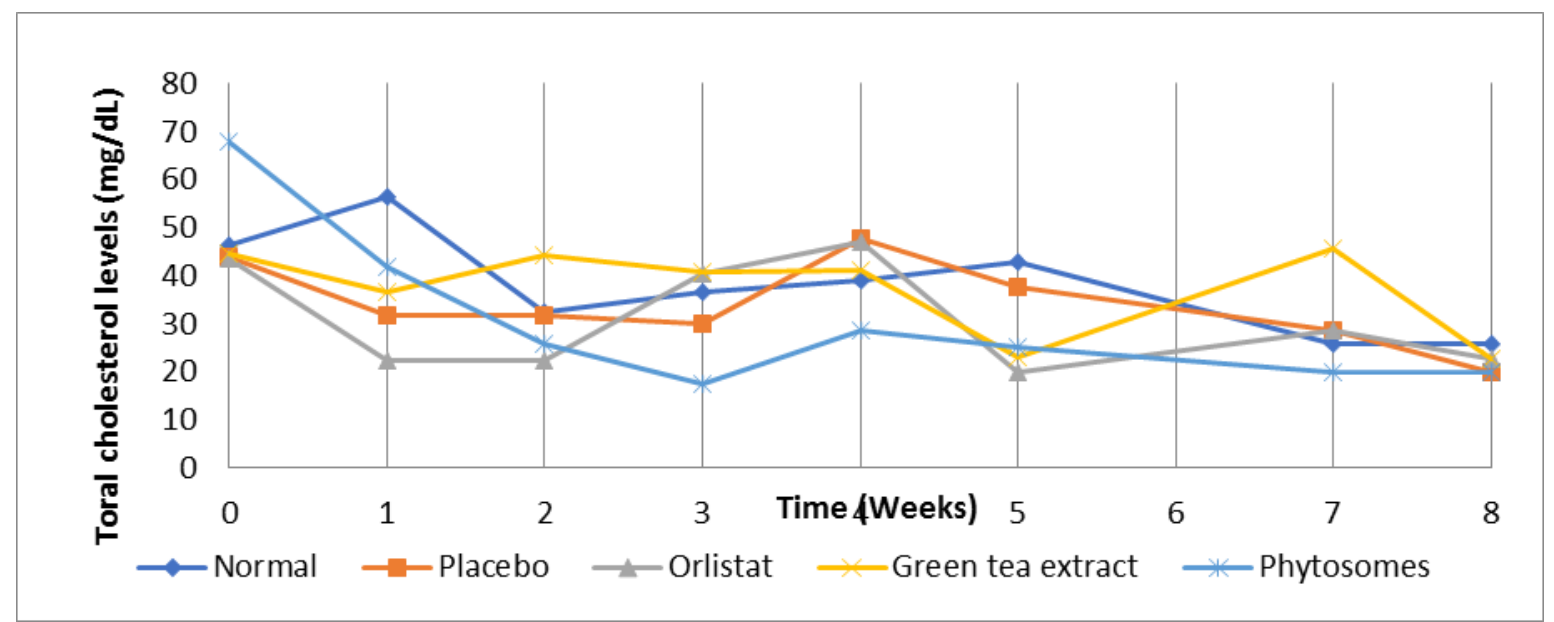

Figure 6. Total rats cholesterol level treated with green tea extract phytosome

\section{CONCLUSION}

Green tea extract phytosomes can be used to influence the inhibit weight gain in rats, although it is not significant ( $p>0.05)$ when compared to orlistat. Phytosome of green tea extract has a better effect than green tea extract in inhibiting the speed of weight gain in rats $(\mathrm{p}<0.05)$.

\section{REFERENCES}

Ahmad, R. S., Butt, M. S., Sultan, M. T., Mushtaq, Z., Ahmad, S., Dewanjee, S., De Feo, V., \& ZiaUl-Haq, M. (2015). Preventive role of green tea catechins from obesity and related disorders especially hypercholesterolemia and hyperglycemia. Journal of Translational Medicine, 13(1), 1-9. https://doi.org/10.1186/s12967-015-0436-x.

Anand, A., Jasneet, C., Mahajan, A., Sharma, N., \& Khurana, N. (2017). Therapeutic potential of epigallocatechin gallate. International Journal of Green Pharmacy, 11(3), 364-368.

Andriany, R. (2015). Preparation of the maltodrekstrinsucinic, polyvinylpyrrolidone and malnitol coprocess preparations used in the tablet formulation is quickly destroyed by the active fraction of the Oyong fruit (Luffa acutangula $(L)$ Roxb) as a metabolic antisindrome. Universitas Indonesia.

Anwar, E., \& Farhana, N. (2018). Formulation and Evaluation of Phytosome-Loaded MaltodextrinGum Arabic Microsphere System for Delivery of Camellia sinensis Extract. Journal of Young 
Pharmacists, 10(2s), S56-S62. https://doi.org/10.7324/JAPS.2018.8809.

Cai, Z. Y., Li, X. M., Liang, J. P., Xiang, L. P., Wang, K. R., Shi, Y. L., Yang, R., Shi, M., Ye, J. H., Lu, J. L., Zheng, X. Q., \& Liang, Y. R. (2018). Bioavailability of tea catechins and its improvement. Molecules, 23(9), 10-13. https://doi.org/10.3390/molecules23092346.

Dewi, K. (2008). Effect of Green Tea Extract on Weight Loss, Triglyceride Levels and Total Cholesterol in Wistar Strain Rats. Journal of Medical Maranatha, 7(2), 1-10. https://doi.org/10.1124/dmd.110.033910.

Fangueiro, J. F., Parra, A., Silva, A. M., Egea, M. A., Souto, E. B., Garcia, M. L., \& Calpena, A. C. (2014). Validation of a high performance liquid chromatography method for the stabilization of epigallocatechin gallate. International Journal of Pharmaceutics, 475(1), 181-190. https://doi.org/https://doi.org/10.1016/j.ijpharm.2014.08.053.

Gadkari, P. V., Shashidhar, M. G., \& Balaraman, M. (2017). Delivery of green tea catechins through Oil-in-Water $(\mathrm{O} / \mathrm{W})$ nanoemulsion and assessment of storage stability. Journal of Food Engineering, 199, 65-76. https://doi.org/https://doi.org/10.1016/j.jfoodeng.2016.12.009.

Gupta, N. K., \& Dixit, V. K. (2011). Development and evaluation of vesicular system for curcumin delivery. Archives of Dermatological Research, 303(2), 89-101. https://doi.org/10.1007/s00403010-1096-6.

Hodgson, A. B., Randell, R. K., \& Jeukendrup, A. E. (2013). Tang \& DeRubeis_SuddenGains.pdf. 9, 129-140. https://doi.org/10.3945/an.112.003269.energy.

Koch, W., Kukula-Koch, W., Komsta, Ł., Marzec, Z., Szwerc, W., \& Głowniak, K. (2018). Green tea quality evaluation based on its catechins and metals composition in combination with chemometric analysis. Molecules, 23(7), 1-19. https://doi.org/10.3390/molecules23071689.

Krook, M. A., \& Hagerman, A. E. (2012). Stability of polyphenols epigallocatechin gallate and pentagalloyl glucose in a simulated digestive system. Food Research International, 49(1), 112116. https://doi.org/https://doi.org/10.1016/j.foodres.2012.08.004.

Kroon, P. A., Clifford, M. N., Crozier, A., Day, A. J., Donovan, J. L., Manach, C., \& Williamson, G. (2004). How should we assess the effects of exposure to dietary polyphenols in vitro? The American Journal of Clinical Nutrition, 80(1), 15-21. https://doi.org/10.1093/ajcn/80.1.15.

Kumar, A., Kumar, B., Singh, S. K., Kaur, B., \& Singh, S. (2017). A review on phytosomes: Novel approach for herbal phytochemicals. Asian Journal of Pharmaceutical and Clinical Research, 10(10), 41-47. https://doi.org/10.22159/ajpcr.2017.v10i10.20424.

Legeay, S., Rodier, M., Fillon, L., Faure, S., \& Clere, N. (2015). Epigallocatechin gallate: A review of its beneficial properties to prevent metabolic syndrome. Nutrients, 7(7), 5443-5468. https://doi.org/10.3390/nu7075230.

Lestari, A., Anwar, E., \& Harahap, Y. (2017). Design and Formulation Quercetin Formula In The Phytosomes System as Novel Drug Delivery. International Journal of Chemtech Research, 10(6), 148-151.

Li, F., Gao, C., Yan, P., Zhang, M., Wang, Y., Hu, Y., Wu, X., Wang, X., \& Sheng, J. (2018). EGCG Reduces Obesity and White Adipose Tissue Gain Partly Through AMPK Activation in Mice . In Frontiers in Pharmacology (Vol. 9, p. 1366).

Malvern Instruments Ltd. (2015). Basic Guide to Particle Characterization. Inform White Paper, 1-24. https://doi.org/https://doi.org/10.1021/ac00110a016.

Maryana, W., Rachmawati, H., \& Mudakhir, D. (2016). Formation of Phytosome Containing Silymarin Using Thin Layer-Hydration Technique Aimed for Oral Delivery. Materials Today: Proceedings, 3, 855-860. https://doi.org/https: /doi.org/10.1016/j.matpr.2016.02.19.

Moon, H.-S., Chung, C.-S., Lee, H.-G., Kim, T.-G., Choi, Y.-J., \& Cho, C.-S. (2007). Inhibitory effect of (-)-epigallocatechin-3-gallate on lipid accumulation of 3T3-L1 cells. Obesity (Silver Spring, Md.), 15(11), 2571-2582. https://doi.org/10.1038/oby.2007.309.

Nagao, T., Hase, T., \& Tokimitsu, I. (2007). A green tea extract high in catechins reduces body fat and cardiovascular risks in humans. Obesity, 15(6), 1473-1483. 
https://doi.org/10.1038/oby.2007.176.

Patel, J., Patel, R., Khambholja, K., \& Patel, N. (2009). An overview of phytosomes as an advanced herbal drug delivery system. Asian Journal of Pharmaceutical Sciences, 4(6), 363-371.

Puligundla, P., Mok, C., Ko, S., Liang, J., \& Recharla, N. (2017). Nanotechnological approaches to enhance the bioavailability and therapeutic efficacy of green tea polyphenols. Journal of Functional Foods, 34, 139-151. https://doi.org/https://doi.org/10.1016/j.jff.2017.04.023.

Rahmadani, R., Nugroho, R. A., \& Sudiastuti. (2015). Effects of Green Tea (Camellia sinensis) and Apple Tea (Mallus sylvestris Mill.) Commercial on the Decrease in Obesity Index and Lipid Profile of Mus Musculus L, Obesity.

Rahmanisa, S., Wulandari, R., Biomedik, B., Kedokteran, F., \& Lampung, U. (2007). Effect of Green Tea Extract on Weight Loss in Adolescents. Majority 5, 2, 106-111.

Riskesdas. (2018). Main results of RISKERDAS 2018 Health. 20-21.

Sayama, K., Lin, S., Zheng, G., \& Oguni, I. (2000). Effects of green tea on growth, food utilization and lipid metabolism in mice. In Vivo (Athens, Greece), 14(4), 481-484.

Yang, C. S., Zhang, J., Zhang, L., Huang, J., \& Wang, Y. (2016). Mechanisms of body weight reduction and metabolic syndrome alleviation by tea. Molecular Nutrition and Food Research, 60(1), 160-174. https://doi.org/10.1002/mnfr.201500428.

Zheng, G., Sayama, K., \& Okubo, T. (2004). Anti-obesity Effects of Three Major Components of Green Tea , Catechins, Caffeine and Theanine, in Mice. In Vivo, 18(1), 55-62.

Zhu, Q. Y., Zhang, A., Tsang, D., Huang, Y., \& Chen, Z.-Y. (1997). Stability of Green Tea Catechins. Journal of Agricultural and Food Chemistry, 45(12), 4624-4628. https://doi.org/10.1021/jf9706080. 
